\title{
Postrhinoplasty Nasal Dorsal Hematoma: An Unexpected Complication
}

\author{
Ceki Paltura (1), Mehmet Külekçi (1) \\ Department of Otolaryngology, Health Sciences University Gaziosmanpaşa Taksim Training and Research Hospital, İstanbul, Turkey
}

Cite this article as: Paltura C, Külekçi M. Postrhinoplasty Nasal Dorsal Hematoma: An Unexpected Complication. JAREM 2018; 8(2): 121-3.

\begin{abstract}
Rhinoplasty is a plastic surgical procedure that requires careful attention at every stage because of its applicability and the different expectations of the patients and the physicians. The steps of the procedure should be followed strictly before, during, and after the operation. This case review is about a patient in whom a hematoma developed at the nasal dorsum because the patient neglected post-surgical care. After the early recognition of this complication, the hematoma was drained and the patient's dressing was reconstructed. After 3 days of follow-up, the hematoma was resolved and the patient discharged. Patients should be closely followed after rhinoplasty as with every surgery. When a complication develops early intervention should be made as soon as possible.
\end{abstract}

Keywords: Rhinoplasty, nasal dorsum, hematoma

ORCID IDs of the authors: C.P. 0000-0002-0971-3643; M.K. 0000-0002-4465-6621.

\section{INTRODUCTION}

Rhinoplasty is a facial surgery that is being increasingly performed for functional or esthetic reasons. The procedure is associated with significant challenges as a result of the level of expectations from patients and physicians as well as applicability issues. Surgical steps should be meticulously followed to achieve the desired outcomes. On the other hand, the procedure is prone to certain complications owing to its nature, and these mainly include functional disorders, deformities due to the transplant or implant materials utilized, skin and soft tissue disorders, and infections (1, 2). Periorbital edema, ecchymosis, and even emphysema may occur in the periorbital area during the early postoperative period, but these should not be considered as complications $(2,3)$ since they generally result from the osteotomy and rasping performed during the correction of the nasal dorsum. Appropriate skin bandages, cold compressions, and head elevation during and after surgery may alleviate most of these minor problems $(4,5)$.

\section{CASE PRESENTATION}

A 19-year-old male patient underwent septorhinoplasty with open technique for saddle nose deformity and nasal airway obstruction (Figures 1, 2). Written informed consent was obtained from the patient. The patient was monitored for 24 hours following surgery. The patient was instructed to apply cold compressions and perform nasal lavage. Except for mild periorbital edema, the patient developed no early postoperative complications, and he was discharged with appropriate antibiotics and analgesics. On follow-up examination 7 days after the procedure, he reported that the plaster cast on the nasal dorsum had detached on postoperative day 5, but he did not return to the clinic for re-attachment. Detailed history revealed that he had not followed the instructions to apply cold compressions.
Edema and hematoma were present in the nasal dorsum (Figure 3), but there were no bleeding and clotting abnormalities. No hematomas or similar lesions were present in the nasal septum. Since the hematoma was only localized to the dorsum, only aspiration with an injector was performed to drain 8-cc of serohemorrhagic fluid. The nasal dorsum was restabilized with a plaster cast and bandages. The patient was admitted to the ward for close clinical observation. He received intravenous antibiotics for prophylaxis against aerobic and anaerobic pathogens. On the $3^{\text {rd }}$ day after admission, the dressings were removed and hematoma was found to have regressed (Figure 4). Dressings and plaster cast were reapplied, appropriate oral antibiotics were prescribed, and the patient was discharged. Although many patients undergoing rhinoplasty experience problems such as edema or ecchymosis, we believe that early detachment of plaster cast and patients' failure to seek medical assistance play a major role in the occurrence of these complications.

\section{DISCUSSION}

The success of rhinoplasty is greatly dependent on proper surgical planning, strict adherence to surgical steps, and quality of postoperative care, which mainly includes stabilization of surgically intervened structures and prevention of postoperative bleeding. Postoperative care starts at the operation table immediately after the termination of the procedure. Stabilization of the skin on the nasal dorsum using adhesive bandages, placement of an appropriate plaster cast, and application of anterior compression to prevent septal hematoma should be conducted even before the patient recovers from anesthesia.

Major early complications of rhinoplasty include edema and ecchymosis in the nasal dorsum and periorbital area $(2,6)$. These morbidities result from soft tissue injuries occurring during the 


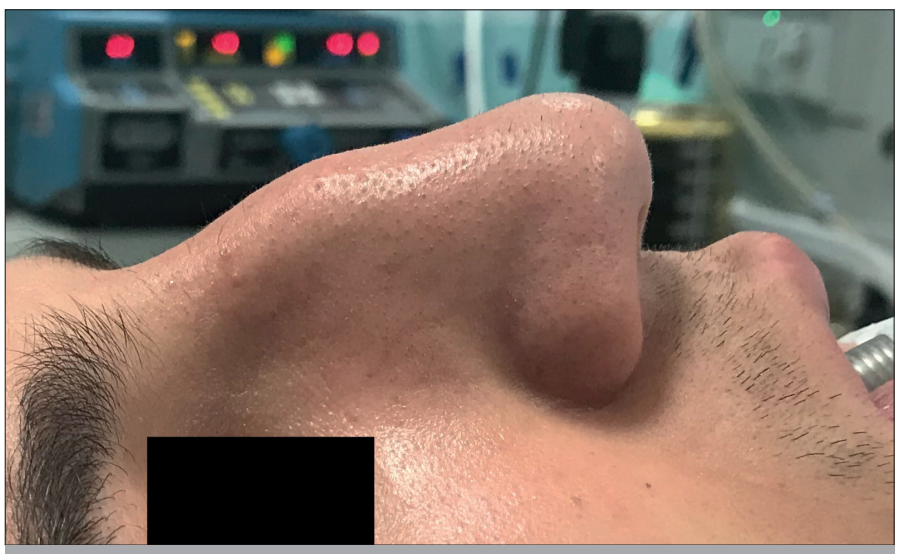

Figure 1. Lateral photograph of the patient on the operation table preoperatively

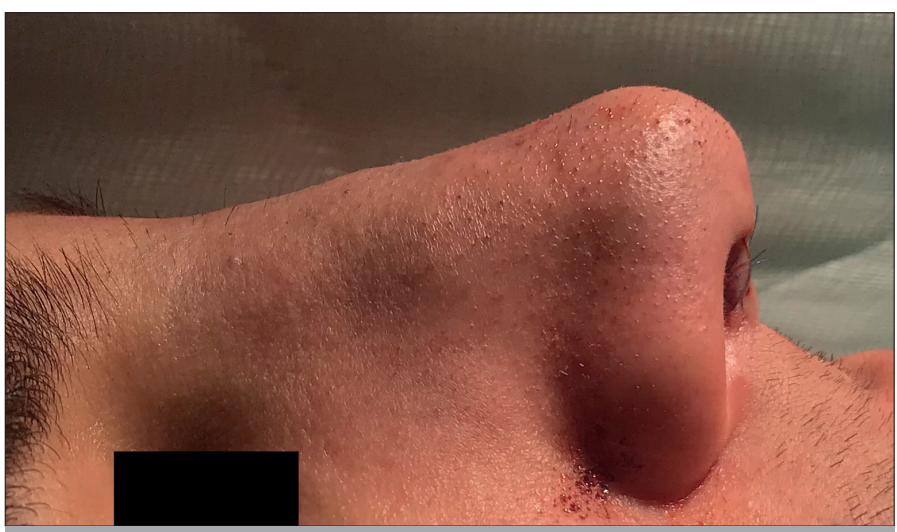

Figure 2. Lateral photograph of the patient on the operation table in the early postoperative period

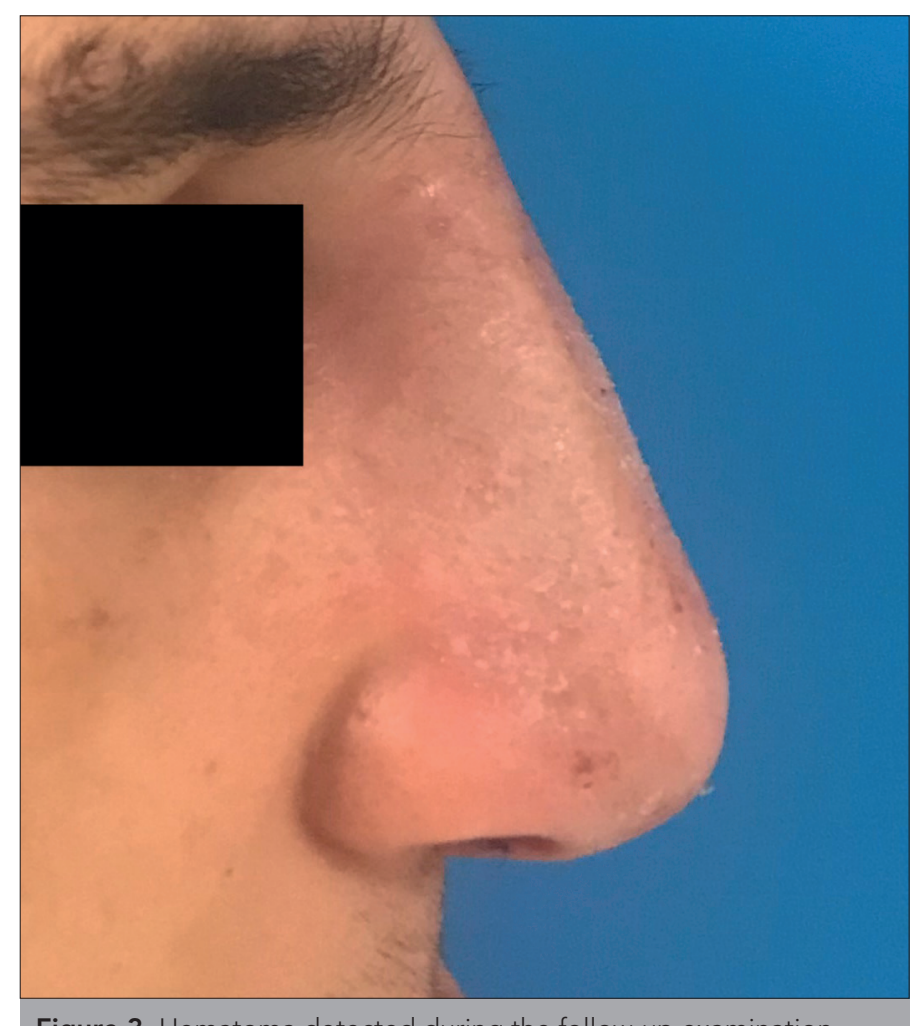

Figure 3. Hematoma detected during the follow-up examination

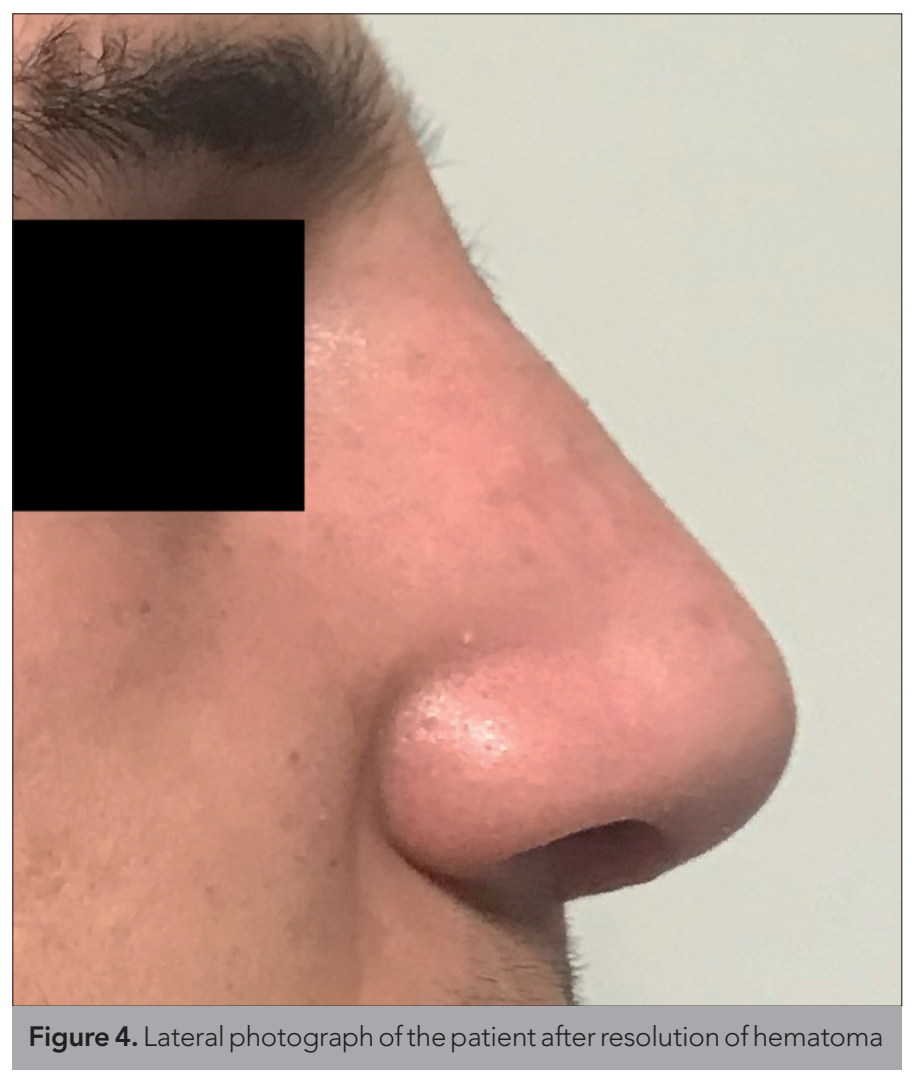

rasping of the osteotomy line or dorsum (7). Although several techniques and instruments have been proposed to decrease edema and ecchymosis, such problems continue to occur in many patients $(4,6,8,9)$. Appropriate technique for nasal skin elevation in the subperichondral and subperiosteal planes and prevention of intraoperative hemorrhage represent the most important perioperative measures to decrease postoperative edema and ecchymosis. Approaches to prevent postoperative edema and ecchymosis include head elevation, compression of the dorsum with bandage application, and application of cold compression (4-6). Cold compressions applied for a minimum duration of 48 hours postoperatively have been reported to decrease edema and ecchymosis (4).

In our patient, no significant complications occurred postoperatively in the first 48 hours, except for periorbital edema, and he was discharged on day 2 after surgery. However, failure to apply cold compressions and perform nasal lavage and detachment of plaster cast earlier than planned resulted in serohemorrhagic fluid collection and hematoma formation in the nasal dorsum. The collected fluid was promptly aspirated during the follow-up visit to our unit. The dorsum was stabilized using adhesive bandages with reapplication of plaster cast, and the patient was admitted. During admission, his head was elevated, cold compressions were applied in the nasal dorsum and around the eyes, and antibiotic prophylaxis was administered against aerobic and anaerobic pathogens. On day 3 of his second admission, the bandages were removed and the dorsum was re-examined. Bandages and plaster cast were reapplied as no new hematoma formation was found. The patient was discharged with appropriate recommendations and prescription of oral antibiotics. 


\section{CONCLUSION}

Similar to other surgical procedures, rhinoplasty requires careful postoperative patient monitoring. Several minor problems, such as mild periorbital edema and ecchymosis, may be observed in the early postoperative period; however, major complications, such as severe hemorrhage and hematoma, can occur that require appropriate patient management. In this regard, postoperative head elevation and application of cold compressions and appropriate dressing bear the utmost clinical significance. In case of bleeding or detachment of plaster cast, as observed in our patient, patients should immediately consult their physician.

Informed Consent: Written informed consent was obtained from the patient who participated in this study.

Peer-review: Externally peer-reviewed.

Author Contributions: Concept- C.P.; Design - C.P.; Supervision - M.K.; Resources - C.P.; Materials - M.K.; Data Collection and/or Processing C.P.; Analysis and/or Interpretation - M.K.; Literature Search - C.P.; Writing Manuscript - C.P.; Critical Review - M.K.

Conflict of Interest: The authors have no conflicts of interest to declare.

Financial Disclosure: The authors declared that this study has received no financial support.

\section{REFERENCES}

1. Rettinger G. Complication or mistake. Fac Plast Surg 1997; 13: 1. [CrossRef]

2. Rettinger G. Risks and complications in rhinoplasty._GMS Curr Top Otorhinolaryngol Head Neck Surg. 2007; 6: Doc08.

3. Sessions RB. Complications of rhinoplasty. Laryngol Rhinol Otol (Stuttg)1983; 62: 185-95. [CrossRef]

4. Taskin U, Yigit O, Bilici S, Kuvat SV, Sisman AS, Celebi S. Efficacy of the combination of intraoperative cold saline-soaked gauze compression and corticosteroids on rhinoplasty morbidity. Otolaryngol Head Neck Surg 2011; 144: 698-702. [CrossRef]

5. Ozucer B, Yildirim YS, Veyseller B, Tugrul S, Eren SB, Aksoy F, et al. Effect of Postrhinoplasty Taping on Postoperative Edema and Nasal Draping: A Randomized Clinical Trial. JAMA Facial Plast Surg 2016; 18: 157-63. [CrossRef]

6. Taşkın Ü, Batmaz T, Erdil M, Aydın S, Yücebaş K. The comparison of edema and ecchymosis after piezoelectric and conventional osteotomy in rhinoplasty. Eur Arch Otorhinolaryngol 2017; 274: 861-5. [CrossRef]

7. Thomas JR, Griner NR, Remmler DJ. Steps for a safer method of osteotomies in rhinoplasty. Laryngoscope 1987; 97: 746-7. [CrossRef]

8. Ilhan AE, Cengiz B, Caypinar Eser B. Double-Blind Comparison of UItrasonic and Conventional Osteotomy in Terms of Early Postoperative Edema and Ecchymosis. Aesthet Surg J 2016; 36: 390-401. [CrossRef]

9. Caglar E, Celebi S, Topak M, Develioglu NO, Yalcin E, Kulekci M. How can periorbital oedema and ecchymose be reduced in rhinoplasty? Eur Arch Otorhinolaryngol 2016; 273: 2549-54. [CrossRef] 